\title{
Improvement in Finite Element Meshes: Heat Transfer in an Infinite Cylinder
}

Madan G. Kittur and Ronald L. Huston

University of Cincinnati

Cincinnati, Ohio

and

Fred B. Oswald

Lewis Research Center

Cleveland, Ohio
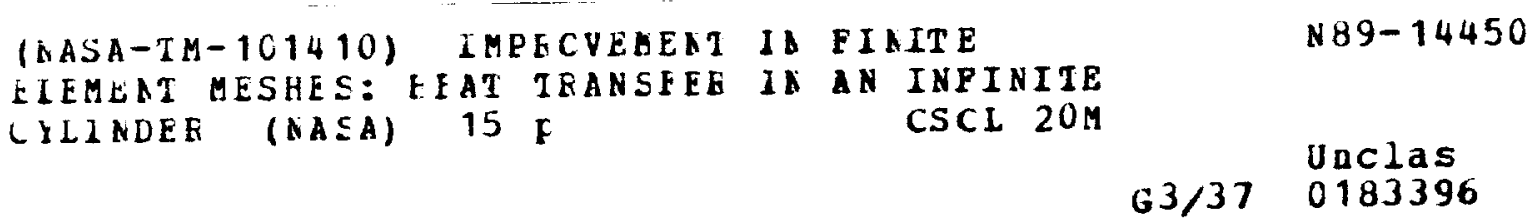

December 1988 

IMPROVEMENT OF FINITE ELEMENT MESHES: HEAT TRANSFER IN AN INFINITE CYLINDER

\author{
Madan G. Kittur* and Ronald L. Huston* \\ University of Cincinnati \\ Department of Mechanical and Industrial Engineering \\ Cincinnati, Ohio 45221 \\ and \\ Fred B. Oswald \\ National Aeronautics and Space Administration \\ Lewis Research Center \\ Cleveland, Ohio 44135
}

\begin{abstract}
SUMMARY
This paper presents an extension of a structural finite element mesh improvement technique to heat conduction analysis. The mesh improvement concept was originally presented by Prager in studying tapered, axially loaded

$\approx$ bars. It was further developed by kittur, et al., who showed that an improved

$\underset{\sim}{\approx}$ mesh can be obtained by minimizing the trace of the stiffness matrix. In this

I paper these procedures are extended and applied to the analysis of heat conduction in an infinitely long hollow circular cylinder.
\end{abstract}

\title{
NOMENCLATURE
}

Ne shape function for element $e$

$n \quad$ number of elements

q temperature gradient, ${ }^{\circ} \mathrm{C} / \mathrm{mm}$

$r$ radius, $\mathrm{mm}$

ro inner radius of the cylinder, $\mathrm{mm}$

$r_{n} \quad$ outer radius of the cylinder, $\mathrm{mm}$

$\mathrm{re}_{\mathrm{e}-1}$ inner radius of element $e, \mathrm{~mm}$

$r e$ inner radius of element $e+l$ or outer radius of element $e, m m$

To temperature at the inner radius, ${ }^{\circ} \mathrm{C}$

$\mathrm{T}_{\mathrm{n}}$ temperature at the outer radius, ${ }^{\circ} \mathrm{C}$

$\left[k_{i j}^{e}\right]$ stiffness matrix of element e

$\kappa$ thermal conductivity, $\mathrm{W} / \mathrm{mm}{ }^{\circ} \mathrm{C}$

*Work funded under NASA Grant NSG-3188. 


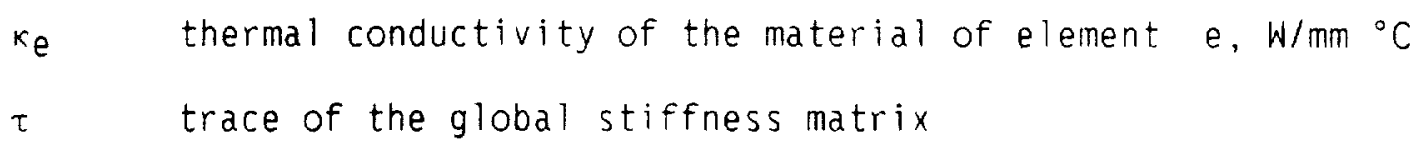

\section{INTRODUCTION}

The finite element analyst is continually confronted with the decision of selecting a "good" mesh for a given problem. Unfortunately there seems to be no simple mesh optimization method which is generally applicable. Recently Kittur, et al., (ref. 1) have proposed a method which provides an improved mesh over a uniform mesh for a broad class of structural problems. The method is based upon the simple procedure of node relocation to minimize the trace of the stiffness matrix. Figure 1 presents a flowchart illustrating the procedure.

An advantage of this method is that the analyst may select the nodal positions prior to solving the equilibrium equations. A posteriori methods such as those of Shephard (ref. 2) and Carroll (ref. 3) can then be used to refine the mesh further.

Kittur, et al., have shown that the minimum trace method produces excellent results for the problem studied by Prager (ref. 4): a uniformly tapered, axially loaded bar. This problem is governed by Poisson's equation with Dirichlet boundary conditions.

In this paper we extend and apply the method to analyze the heat conduction through the cross section of an infinitely long hollow circular cylinder. For this problem, the governing equation is also of the form of Poisson's equation. In this case, however, since no heat sources are considered the governing equation reduces to Laplace's equation. Both Dirichlet and mixed boundary conditions are considered. The results are compared with analytical solutions and with finite element solutions obtained with a uniform mesh.

\section{CONFIGURATION AND PROBLEM DEFINITION}

Consider a hollow circular cylinder of infinite length having inner and outer radii: $r_{0}$ and $r_{n}$. Let the thermal conductivity be $k$, and the temperatures at the inner and outer radii be $T_{0}$ and $T_{n}$ respectively. The governing equation for the temperature distribution along a radial line is:

$$
\frac{d}{d r}\left[r \kappa \frac{d T}{d r}\right]=0
$$

The boundary conditions are:

and

$$
T=T_{0} \text { at } r=r_{0}
$$

$$
T=T_{n} \text { at } r=r_{n}
$$

The solution of equation (1) subject to equation (2) is:

$$
T=T_{n}+\left(T_{0}-T_{n}\right) \frac{\ln \left(\frac{r_{n}}{r}\right)}{\ln \left(\frac{r_{n}}{r_{0}}\right)}
$$


Next, suppose that the temperature gradient at the inner surface i: specified as: $q_{0}$. The boundary conditions are then:

and

$$
\frac{d T}{d r}=q_{0} \quad \text { at } \quad r=r_{0}
$$

In this case the solution of equation (1) is:

$$
T=T_{n}-r_{0} q_{0} \ln \left(\frac{r_{n}}{r}\right)
$$

\section{FINITE ELEMENT FORMULATION AND MESH OPTIMIZATION}

Figure 2 shows the finite element model. Its consists of a series of annular elements. For element (e) let the inner and outer radi $i$ be $r e$ and $r_{e+1}$. The entries of the element stiffness matrix are:

$$
\left[k_{i j}^{e}\right]=2 \pi k e \int_{r_{e}}^{r} e+1 \quad r \frac{d N_{i}^{e}}{d r} \frac{d N_{j}^{e}}{d r} d r
$$

where $\kappa_{e}$ is the element conductivity constant and where the element shape functions $\mathrm{N}_{1}^{\mathrm{e}}$ and $\mathrm{N}_{2}^{\mathrm{e}}$ are:

$$
N_{1}^{e}=\frac{\left(r_{e+1}-r\right)}{\left(r_{e+1}-r_{e}\right)}
$$

and

$$
N_{2}^{e}=\frac{\left(r-r_{e}\right)}{\left(r_{e+1}-r_{e}\right)}
$$

By carrying out the indicated operations the element stiffness matrix becomes:

$$
\left[k_{i j}^{e}\right]=S_{e}\left[\begin{array}{cc}
1 & -1 \\
-1 & 1
\end{array}\right]
$$

where $S_{e}$ is defined as:

$$
S_{e}=\pi \kappa_{e}\left(\frac{r_{e+1}+r_{e}}{r_{e+1}-r_{e}}\right)
$$


Hence the trace $\tau$ of the global stiffness matrix is:

$$
\tau=2 \sum_{e=1}^{n} s_{e}
$$

where $n$ is the number of elements.

The trace may be minimized with respect to the nodal coordinates by setting the partial derivative of $\tau$ with respect to $r$ e equal to zero and solving for the ratio $r_{e+l} / r_{e}$ :

$$
\frac{\partial \tau_{e}}{\partial r_{e}}=0
$$

Since the derivative of a sum is the sum of the derivatives, and assuming that the conductivity $k$ is uniform thorugh the body (i.e.: $\kappa_{e-l}=\kappa_{e}=\kappa_{e}+1$ ), (11) becomes:

$$
\frac{\partial}{\partial r_{e}}\left[. \cdot+\frac{r_{e}+r_{e-1}}{r_{e}-r_{e-1}}+\frac{r_{e+1}+r_{e}}{r_{e+1}-r_{e}}+\cdots \cdot\right]=0
$$

which simplifies to:

$$
\frac{-2 r_{e-1}}{\left(r_{e}-r_{e-1}\right)^{2}}+\frac{2 r_{e+1}}{\left(r_{e+1}-r_{e}\right)^{2}}=0
$$

Inverting (13) and factoring:

$$
\frac{r_{e}^{2}\left(\frac{r_{e}+1}{r_{e}}-1\right)^{2}}{r_{e+1}}=\frac{r_{e-1}\left(\frac{r_{e}}{r_{e-1}}-1\right)^{2}}{r_{e-1}}
$$

Rearranging:

$$
\left(\frac{r_{e}}{r_{e-1}}\right)\left(\frac{r_{e+1}}{r_{e}}-1\right)^{2}=\left(\frac{r_{e}+1}{r_{e}}\right)\left(\frac{r_{e}}{r_{e}-1}-1\right)^{2}
$$

Let $A=\frac{r_{e+1}}{r_{e}}$ and $B=\frac{r_{e}}{r_{e-1}}$, then (15) becomes:

$$
B(A-1)^{2}=A(B-1)^{2}
$$

or:

$$
A B(A-B)-(A-B)=0
$$


thus:

$$
(A-B)(A B-1)=0
$$

Equation (18) implies that either $(A-B)=0$ or $(A B-1)=0$. If $(A B-1)=0$, then $A B=1$, which means $\frac{r_{e+1}}{r_{e}} \frac{r_{e}}{r_{e-1}}=1=\frac{r_{e+1}}{r_{e-1}}$ which is impossible. Therefore $(A-B)=0$, which implies that $A=B$. This leads to the relatively simple relation:

$$
\frac{r_{e+1}}{r_{e}}=\frac{r_{e}}{r_{e-1}}=Y
$$

where $y$ is a constant. The optimal nodal positions are found through repeated use of equation (19):

$$
\frac{r_{2}}{r_{1}}=\frac{r_{1}}{r_{0}}=\frac{r_{3}}{r_{2}}=\frac{r_{2}}{r_{1}}=\frac{r_{e+1}}{r_{e}}=\frac{r_{e}}{r_{e-1}}=\frac{r_{n}}{r_{n-1}}=\frac{r_{n-1}}{r_{n-2}}=\gamma
$$

Then:

$$
\begin{aligned}
& \frac{r_{n}}{r_{0}}=\left(\frac{r_{n}}{r_{n-1}}\right)\left(\frac{r_{n-1}}{r_{n-2}}\right) \cdot \cdot\left(\frac{r_{e+1}}{r_{e}}\right)\left(\frac{r_{e}}{r_{e-1}}\right) \cdot \cdot\left(\frac{r_{3}}{r_{2}}\right)\left(\frac{r_{2}}{r_{1}}\right)\left(\frac{r_{1}}{r_{0}}\right)
\end{aligned}
$$

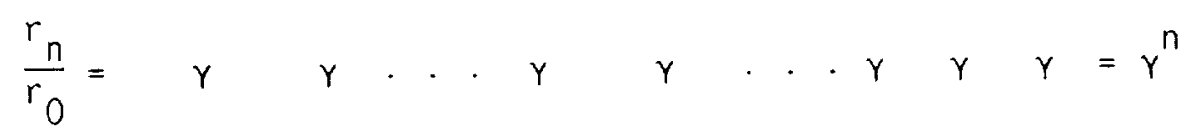

thus: $r_{n}=r_{0} \gamma^{n}$ and $y=\left(r_{n} / r_{0}\right)^{1 / n}$. Changing $n$ to $e$, we have: $r_{e}=r_{0} \gamma^{e}$ or:

$$
r_{e}=r_{0}\left(\frac{r_{n}}{r_{0}}\right)^{e / n}
$$

\section{NUMERICAL EXAMPLES}

\section{Example 1}

To illustrate the effectiveness of the method consider an annular cylinder with the following temperatures specified on the boundaries and made from a material with constant thermal conductivity $k=\kappa_{e}=1.0$.

$$
\begin{array}{lll}
T=T_{0}=100{ }^{\circ} \mathrm{C} & \text { at } & r_{0}=20 \mathrm{~mm} \\
T=T_{n}=0{ }^{\circ} \mathrm{C} & \text { at } & r_{n}=50 \mathrm{~mm}
\end{array}
$$


Consider two finite element models, each with four linear elements and five nodes: The first model (designated "Uniform Mesh") has equally spaced nodes. The second model (designated "Improved Mesh") has its nodal spacing governed by equation (23). The objective is the determination of the internal temperature distribution.

The solutions of the finite element governing equations lead to the results listed in table I. The error at the nodes is defined as the difference between the theoretical results and the finite element results. In order to compare the error distribution among the elements, rms errors were calculated using 50 uniformly spaced points through the thickness of each element. Each element's linear shape function was used to compute the temperature at any point along the element from nodal temperature values. Error values were calculated at each point from the difference between theoretical and finite element temperature values. The rms errors are shown beside the nodal errors in table I. The standard deviation of the within-element rms errors is shown at the bottom of table I with the overall rms error for the model which was calculated using 200 uniformly-spaced points through the model. (These are not quite the same points used for computing the within-element rms errors.)

The theoretical solution for this example (from eq. 3 ) is shown in figure 3. The nodal values for both models are superimposed on the theoretical solution. At this scale, differences between nodal and FEM values are much too small to be seen in the figure. The errors for the two models are plotted on an expanded scale in figure 4. Since linear elements were used, the errors tend to increase towards the center of each element (away from the nodes).

The uniform mesh has relatively small errors at the nodes and greater errors near the inner surface of the annular cylinder where the temperature gradient is greatest. The improved mesh is found to have zero errors at the nodes and a uniform distribution of errors between elements. The overall rms error of the improved mesh is 23 percent less than that of the uniform mesh.

\section{Example 2}

Next, consider the same cylinder but let the temperature gradient be specified on the inner boundary. Specifically, let the boundary conditions be:

$$
\begin{array}{lll}
\frac{d T}{d r}=-5.4567833^{\circ} \mathrm{C} / \mathrm{mm} & \text { at } & r_{0}=20 \mathrm{~mm} \\
T=T_{n}=0{ }^{\circ} \mathrm{C} & \text { at } & r_{n}=50 \mathrm{~mm}
\end{array}
$$

(The boundary conditions were chosen to yield a nearly identical theoretical temperature distribution as in the first example.)

Table II shows the comparison between the finite element solution and the theoretical values of the temperature. Once again the improved mesh shows a more uniform distribution of rms errors between elements and the overall rms error is lower (by 15 percent) than that of the uniform mesh. The errors for the two models are plotted in figure 5 . 


\section{Example 3}

Since the temperature gradient is specified at the inner boundary, it is also of interest to know how the values of the temperature gradients obtained using the two finite element meshes compare with each other and with the theoretical values. table III provides such a comparison. The errors as plotted in figure 6 are much greater (relatively) than in the previous examples, especially at the nodes. Note that the largest error is at the inside radius where the derivative boundary condition is applied. Generally the Neumann boundary conditions are not strongly satisfied in the finite element method (ref. 5). Therefore, in general, the FE method is not well suited for gradient-type problems. The improved mesh shows a slightly more uniform distribution of rms errors between elements and the overall rms error is also slightly lower (by 7 percent).

\section{DISCUSSION}

The numerical examples show that the "improved" mesh defined by equation (23) produces results which are in better agreement with the theoretical values than those obtained using the uniform mesh. Therefore, the mesh defined by equation (12) is an improvement over the uniform mesh for both the temperaturefixed boundary conditions and for the mixed boundary conditions.

In Example 1 , the values of the stiffness matrix traces of the uniform and improved meshes are 74.6667 and 70.1520 , respectively. This indicates that for this example the trace is only moderately sensitive to the nodal locations. More dramatic differences in the results will occur in problems where the trace is more sensitive to changes in the nodal positions. This will occur in problems with less regular geometry.

In the conventional finite element method, if a model with $n$ degrees of freedom is refined by adding nodes, a new stiffness matrix needs to be constructed. In general the new stiffness matrix is different in form from the original stiffness matrix. However, in the "hierarchical" approach, new elements are constructed so that the original $n \times n$ stiffness matrix forms a submatrix of the new stiffness matrix. In this case, therefore, it is necessary to compute only the stiffness entries corresponding to the new degrees of freedom. This reduces the computing time in assembly. (See Zienkiewicz (ref. 6) for a more detailed discussion on hierarchical finite elements.) Since error estimation in the hierarchical approach has been established, we can take advantage of the error analyses in studying conventional finite elements.

Consider a finite element model with $n$ degrees of freedom (d.o.f). If the mesh is to be refined by introducing additional nodes (h-type refinement), then it is necessary to know the expected improvement in error before a refinement step is undertaken. 0.C. Zienkiewicz, et al. (ref. 7) and Peano, et al. (ref. 8) have shown that if the $n+l^{\text {th }} d .0 . f$. is to be introduced hierarchically, then the error in the energy norm is:

$$
\left\|e_{n, 1}\right\|^{2}=\frac{\left(f_{n+1}-k_{n+1, n} u_{n}\right)^{2}}{k_{n+1, n+1}}
$$


where $f_{n+1}$ is the force corresponding to the $n+1$ th $d .0 . f ., K_{n+1}, n+1$ is the stiffness of the $n+1^{\text {th }}$ d.o.f $k_{n+1, n}$ is the off-diagonal stiffness relating the $n+l$ th d.o.f. to the original $n$ d.o.f. system, and $u_{n}$ is the array of nodal displacements of the $n$ d.o.f. system. The subscripts $n, 1$ of the error e refer to the $n$ original d.o.f. and the new d.o.f.

Zienkiewicz (ref. 6) has used the above error relation to define an error indicator in the form:

$$
n_{n, 1}^{2}=\frac{\left(\int_{\Omega} \frac{\left.\zeta N_{n+1} d \Omega\right)^{2}}{k_{n+1, n+1}}\right.}{-}
$$

where $\zeta$ is the finite element residual.

In an adaptive refinement strategy, these indicators are normally calculated for all the d.o.f. corresponding to the next refinement. The indicators serve the purpose of identifying the region where refinement is necessary.

Next, the error corresponding to the previous iteration wherein the $n$th d.o.f. was added is:

$$
\left\|e_{n-1,1}\right\|^{2}=\frac{\left(f_{n}-k_{n, n-1} u_{n-1}\right)^{2}}{k_{n, n}}
$$

The corresponding error indicator is:

$$
n_{n-1,1}^{2}=\frac{\left(\int_{\Omega} \zeta N_{n} d \Omega\right)^{2}}{K_{n, n}}
$$

These derivations are for hierarchical finite elements. However, the error with conventional finite elements will be of similar form (ref. 6 ).

The most general method of generating a good grid is to have an equal distribution of some specified weight function. (See Eiseman (ref. 9) for a complete discussion on adaptive grid generation.) Often, the error in the finite element solution is used as the weight function (ref. 10). Therefore the objective is to distribute the error equally among all elements. However, the value of the residual $\zeta$ can be obtained only after the equilibrium equations are solved. Nevertheless, one way of obtaining an equi-distribution of error a priori is by having a uniform element stiffness. As a consequence $\zeta$ will be nearly uniform among the elements. The trace minimization procedure developed herein produces such a result. Note that each of the ratios in the optimality condition, equation (19), is a constant $\gamma$.

$$
\frac{r_{1}}{r_{0}}=\frac{r_{2}}{r_{1}}=\ldots .=\frac{r_{e+1}}{r_{e}}=\ldots . .=\frac{r_{n}}{r_{n-1}}=\gamma
$$


Substituting into equation ( 9 ), the element stiffness coefficient is:

$$
S_{e}=\pi \kappa_{e} \frac{Y+1}{Y-1}
$$

which is a constant. Therefore the trace minimization procedure produces a uniform element stiffness.

Finally, observe the graphs of the errors in figures 4 to 6 . As mentioned earlier, the errors are more equally distributed with the improved mesh while there is a skewed distribution with the uniform nesh. In tables I to III, the standard deviation of the within-element rms errors is lower for the improved mesh than it is for the uniform mesh. Therefore, in all cases, the improved mesh distributes the error more uniformly than the uniform mesh. The rms errors are exactly equal (within precision of calculation) in the case where temperatures are specified at the boundaries. Therefore the mesh obtained in this case is optimal. Similar results, however are not obtained in the case where both temperature and gradient of temperature are specified because of the inability of FEM to strongly satisfy the Neumann boundary conditions. Nevertheless, it demonstrates the usefulness of the trace minimization procedure in a priori grid refinement.

\section{CONCLUSIONS}

The new method of finite-element grid improvement based on the minimization of the trace of the stiffness method has been extended to the problem of heat transfer in a solid body. In elasticity problems, this procedure is equivalent to minimizing the potential energy of the model by dividing the strain energy equally among the elements. The following conclusions were made:

1. Nodal positioning obtained by minimizing the trace of the stiffness matrix leads to an improved mesh over that obtained by uniform positioning of the nodes.

2. Since trace minimization is an a priori method, the mesh may be refined without solving the finite element problem. This makes the minimization procedure computationally inexpensive to perform. The mesh resulting from trace minimization may be used as a starting mesh for other mesh refinement procedures such as element division or element enhancement ( $h$-methods or $p$-methods).

3. The method does not give satisfactory results for analyses in which both temperature and gradient of temperature are specified boundary conditions due to the inability of the FEM to strongly satisfy Neumann boundary conditions.

\section{REFERENCES}

1. Kittur, M.G.; Huston, R.L.; and Oswald, F.B.: Finite-Element Grid Improvement by Minimization of Stiffness Matrix Trace. NASA TM-100255, (AVSCOM TP-87-C-4), 1987.

2. Shephard, M.S.: Finite Element Grid Optimization with Interactive Computer Graphics. Ph.D. Dissertation, Cornell University, 1979. 
3. Carroll, W.E.; and Barker, R.M.: A Theorem for Optimum Finite Element Idealizations. Int. J. Solids Struct., vol. 9, no. 7, July 1973. pp. 883-895.

4. Prager, W.: A Note on the Optimal Choice of Finite Element Grids. Comput. Methods App 1. Mech. Eng., vol. 6, Nov. 1975, pp. 363-366.

5. Thomasset, F.: Implementation of Finite Element Methods for Navier-Stokes Equations. Springer-Verlag, 1981, p. 22.

6. Zienkiewicz, 0.C., et al.: Hierarchial Finite Element Approaches, Error Estimates and Adaptive Refinements. The Mathematics of Finite Elements and Applications IV, J.R. Whiteman, ed., Academic Press, 1982, pp. 313-346.

7. Zienkiewicz, O.C.; and Craig, A.W.: Adaptive Refinement, Error Estimates, Multigrid Solution, and Hierarachic Finite Element Method Concepts. Accuracy Estimates and Adaptive Refinements in Finite Element Computations, I. Babuska, et al., eds., John Wiley \& Sons, 1986.

8. Peano, A., et al: Self Adaptive Convergence at the Crack Tip of a Dam Buttress. Numerical Methods in Fracture Mechanics, A.R. Luxmoore and D.R.J. Owen, eds., Swansea, 1979, pp. 268-280.

9. Eiseman, P.R.: Adaptive Grid Generation. Comput. Methods App 1. Mech. Eng., vol. 64, nos. 1-3, Oct. 1987, pp. 321-376.

10. Gago, J.P. de S.R.; et al.: A Posteriori Error Analysis and Adaptive Processes in the Finite Element Method: Part II - Adaptive Mesh

Refinement. Int. J. Numer. Methods Eng., vol. 19, no. 11, Nov. 1984, pp. $1621-1656$. 
TABLE I. - COMPARISON BETWEEN UNIFORM MESH, IMPROVED MESH. AND THEORETICAL VALUES FOR TEMPERATURE SPECIFIEO BOUNDARY CONOITION PROBLEM

\begin{tabular}{|c|c|c|c|c|c|c|c|}
\hline \multirow{2}{*}{$\begin{array}{l}\text { Radius, } \\
\mathrm{mm}\end{array}$} & \multicolumn{3}{|c|}{ Temperature value, ${ }^{\circ} \mathrm{C}$} & \multicolumn{2}{|c|}{ Uniform mesh error } & \multicolumn{2}{|c|}{ Improved mesh error } \\
\hline & $\begin{array}{l}\text { Uniform } \\
\text { mesh }\end{array}$ & $\begin{array}{l}\text { Improved } \\
\text { mesh }\end{array}$ & Theory & At node & $\begin{array}{l}\text { In element } \\
\text { rms }\end{array}$ & At node & $\begin{array}{c}\text { In element } \\
\text { rms }\end{array}$ \\
\hline $\begin{array}{l}20 . \\
25.1487 \\
27.5 \\
31.6228 \\
35 . \\
39.7635 \\
42.5 \\
50 .\end{array}$ & $\begin{array}{r}100 . \\
65.3550 \\
39.0247 \\
\begin{array}{l}17.7907 \\
0 .\end{array}\end{array}$ & $\begin{array}{r}100 . \\
75.0000 \\
-50.0000 \\
25.0000 \\
0 .\end{array}$ & $\begin{array}{l}100 . \\
75 . \\
65.2153 \\
50 . \\
38.9260 \\
25 . \\
17.7366 \\
0 .\end{array}$ & $\begin{array}{c}0 . \\
-0.1096 \\
-0.0988 \\
-0.0511 \\
0 .\end{array}$ & $\begin{array}{l}\cdots \\
\cdots \\
\cdots \\
0.0+179 \\
0 .+688 \\
-0.1122 \\
0.2857\end{array}$ & \begin{tabular}{l}
0.0000 \\
0.0000 \\
\hdashline 0.0000 \\
\hdashline 0.0000 \\
-0.0000
\end{tabular} & \begin{tabular}{l}
$\overline{0.5171}$ \\
\hdashline 0.5171 \\
-0.5171 \\
\hdashline 0.5171
\end{tabular} \\
\hline $\mathrm{S}$ & iatio & within- & $\begin{array}{l}\text { ent } \mathrm{rms} \\
\mathrm{rall} \mathrm{rm}\end{array}$ & $\begin{array}{l}\text { erors } \\
\text { error }\end{array}$ & $\begin{array}{l}0 . \quad 309 \\
0 .+801\end{array}$ & & $\begin{array}{l}0.00001 \\
0.5210\end{array}$ \\
\hline
\end{tabular}

TABLE II. - COMPARISON BETWEEN UNIFORM MESH, IMPROVED MESH, AND THEORETICAL VALUES FOR TEMPERATURE/TEMPERATURE-GRADIENT SPECIFIED BOUNDARY CONDITIONS

\begin{tabular}{|c|c|c|c|c|c|c|c|}
\hline \multirow{2}{*}{$\begin{array}{l}\text { Radius, } \\
\mathrm{mm}\end{array}$} & \multicolumn{3}{|c|}{ Temperature value, ${ }^{2} \mathrm{C}$} & \multicolumn{2}{|c|}{ Uniform mesh error } & \multicolumn{2}{|c|}{ Improved mesh error } \\
\hline & $\begin{array}{l}\text { Uniform } \\
\text { mesh }\end{array}$ & $\begin{array}{l}\text { Improved } \\
\text { mesh }\end{array}$ & Theory & At node & $\begin{array}{l}\text { In element } \\
\text { rms }\end{array}$ & At node & $\begin{array}{l}\text { In element } \\
\text { rms }\end{array}$ \\
\hline $\begin{array}{l}20 . \\
25.1487 \\
27.5 \\
31.6228 \\
35 . \\
39.7635 \\
42.5 \\
50 .\end{array}$ & $\begin{array}{c}99.4772 \\
65.0133 \\
38.8207 \\
17.6977 \\
0 .\end{array}$ & $\begin{array}{c}99.5700 \\
74.6775 \\
49.7850 \\
-24.8925 \\
-0 .\end{array}$ & $\begin{array}{l}100 . \\
75 . \\
65.2453 \\
50 . \\
38.9260 \\
25 . \\
17.1360 \\
0 .\end{array}$ & $\begin{array}{l}0.5228 \\
-0.2321 \\
0.1053 \\
0.0341 \\
0 .\end{array}$ & $\begin{array}{l}0.6786 \\
0.073 \\
0.4273 \\
0.3082 \\
0.3100\end{array}$ & $\begin{array}{l}0.4300 \\
0.3225 \\
0.2150 \\
-0.1075 \\
-0.0000\end{array}$ & $\begin{array}{l}0.2403 \\
0.2980 \\
-0.3782 \\
0.9694\end{array}$ \\
\hline \multicolumn{5}{|c|}{$\begin{array}{r}\text { Standard deviation of within-element rms errors } \\
\text { overali rms error }\end{array}$} & $\begin{array}{l}0.1920 \\
0.4494\end{array}$ & & $\begin{array}{l}0.0996 \\
0.3803\end{array}$ \\
\hline
\end{tabular}

TABLE III. - COMPARISON BETWEEN UNIFORM MESH, IMPROVED MESH, AND THEORETICAL TEMPERATURE GRADIENT VALUES FOR TEMPERATURE/TEMPERATURE GRADIENT SPECIFIEO BOUNDARY CONDITIONS

\begin{tabular}{|c|c|c|c|c|c|c|c|}
\hline \multirow{2}{*}{$\begin{array}{l}\text { Radius, } \\
\text { mm }\end{array}$} & \multicolumn{3}{|c|}{ Temperature gradient, ${ }^{2} \mathrm{C} / \mathrm{mm}$} & \multicolumn{2}{|c|}{ Uniform mesh error } & \multicolumn{2}{|c|}{ Improved mesh error } \\
\hline & $\begin{array}{l}\text { Uniform } \\
\text { mesh }\end{array}$ & $\begin{array}{l}\text { Improved } \\
\text { mesh }\end{array}$ & Theory & At node & $\begin{array}{l}\text { In element } \\
\text { rms }\end{array}$ & At node & $\begin{array}{c}\text { In element } \\
\text { rms }\end{array}$ \\
\hline $\begin{array}{l}20 . \\
25.1487 \\
27.5 \\
31.6228 \\
35 . \\
39.7635 \\
42.5 \\
50 .\end{array}$ & $\begin{array}{l}-4.5952 \\
--3.4923 \\
-2.8164 \\
-2 . \\
-2.3597 \\
-2.3597\end{array}$ & $\begin{array}{l}-4.8347 \\
-3.84490 \\
-3.0578 \\
--2.4317 \\
-2.4317\end{array}$ & $\begin{array}{l}-5.4568 \\
-4.3396 \\
-3.9686 \\
-3.4512 \\
-3.1182 \\
-2.7446 \\
-2.5679 \\
-2.1827\end{array}$ & $\begin{array}{c}0.8616 \\
-0.4762 \\
-0.3018 \\
0.2082 \\
-0.1110\end{array}$ & \begin{tabular}{l}
$0.1,029$ \\
\hdashline 0.1594 \\
\hdashline $0 . \therefore 392$ \\
0.1134
\end{tabular} & $\begin{array}{r}0.6220 \\
-0.4947 \\
-0.3934 \\
-0.3129 \\
-0.2490\end{array}$ & $\begin{array}{l}---1 \overline{0} \\
0.5183 \\
0.4122 \\
0.3278 \\
0.1653\end{array}$ \\
\hline \multicolumn{5}{|c|}{$\begin{array}{r}\text { Standard deviation of within-element rms errors } \\
\text { Overall rms error }\end{array}$} & $\begin{array}{l}0.2086 \\
0.2755\end{array}$ & & $\begin{array}{l}0.1490 \\
0.3478\end{array}$ \\
\hline
\end{tabular}



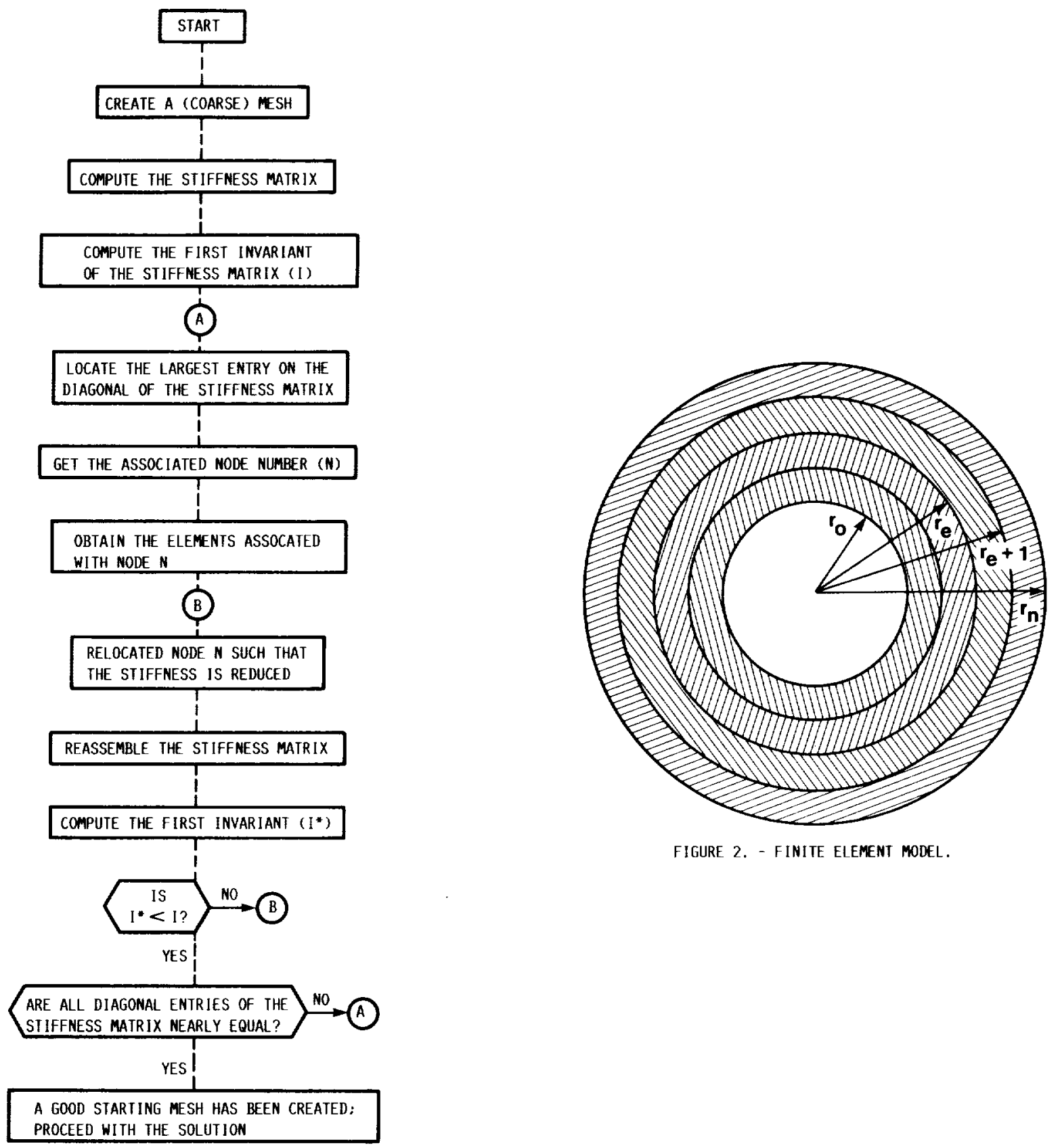

FIGURE 2. - FINITE ELEMENT MODEL.

FIGURE 1. - FLOWCHART FOR MESH IMPROVEMENT PROCEDURE. 


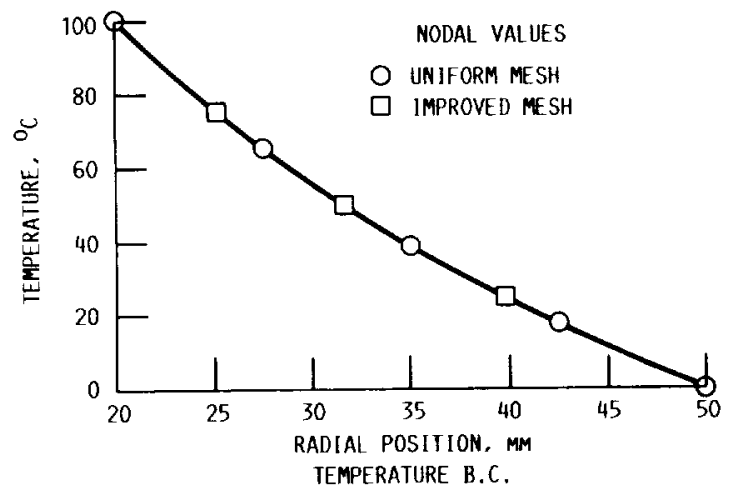

FIGURE 3. - SAMPLE PROBLEM: THEORETICAL AND NODAL TEMPERATURE VALUES.

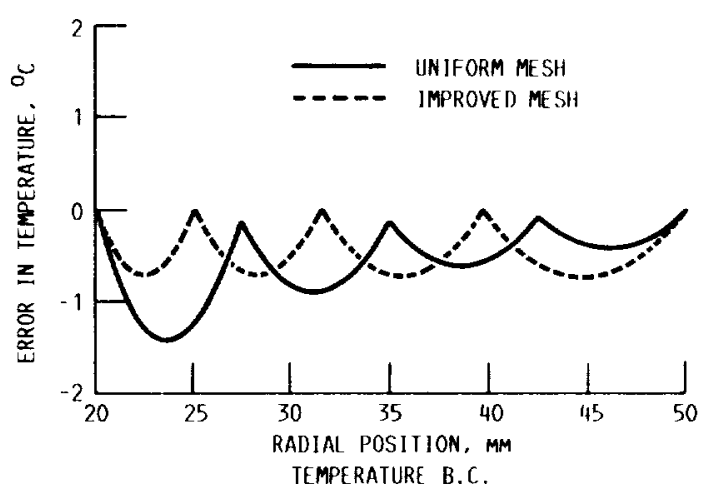

FIGIJRE 4. - EXAMPLE 1 (TEMPERATURE/TEMPORARY BOUNDARY CONDITIONS): ERRORS IN FEM RESULTS F OR CYL INDER TEMPERATURE.

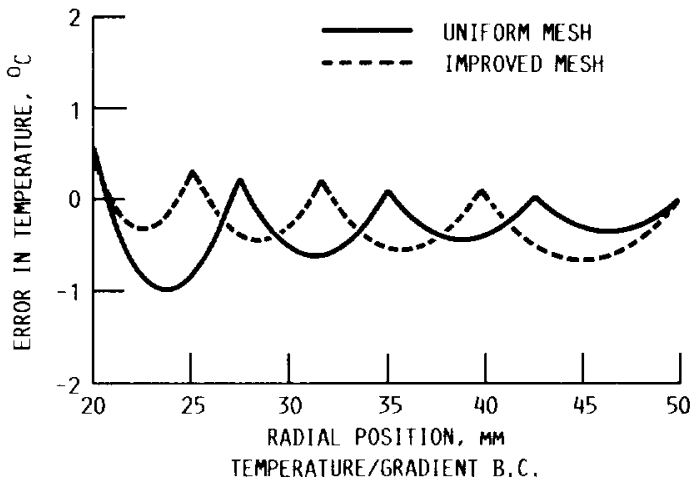

FIGURE 5. - EXAMPLE 2 (GRADIENT/TEMPERATURE BOUNDARY CONDITIONS): ERRORS IN FEM RESULTS FOR CYLINDER TEMPERATURE.

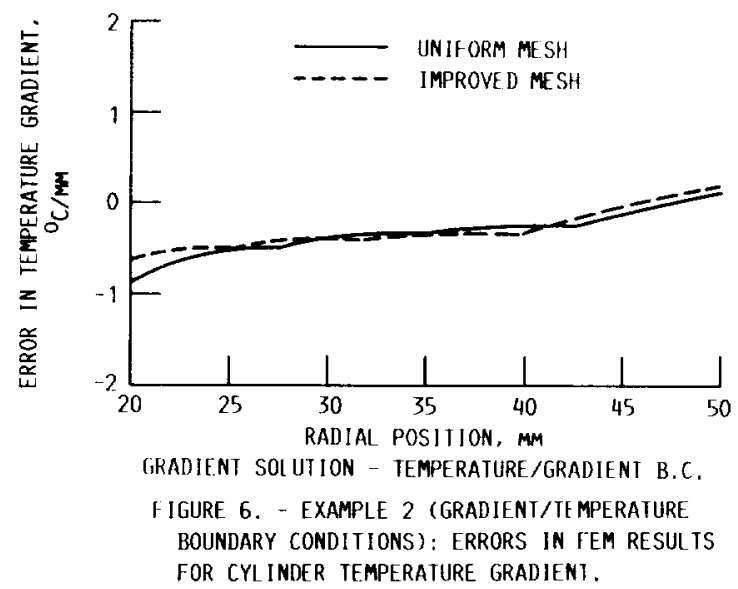




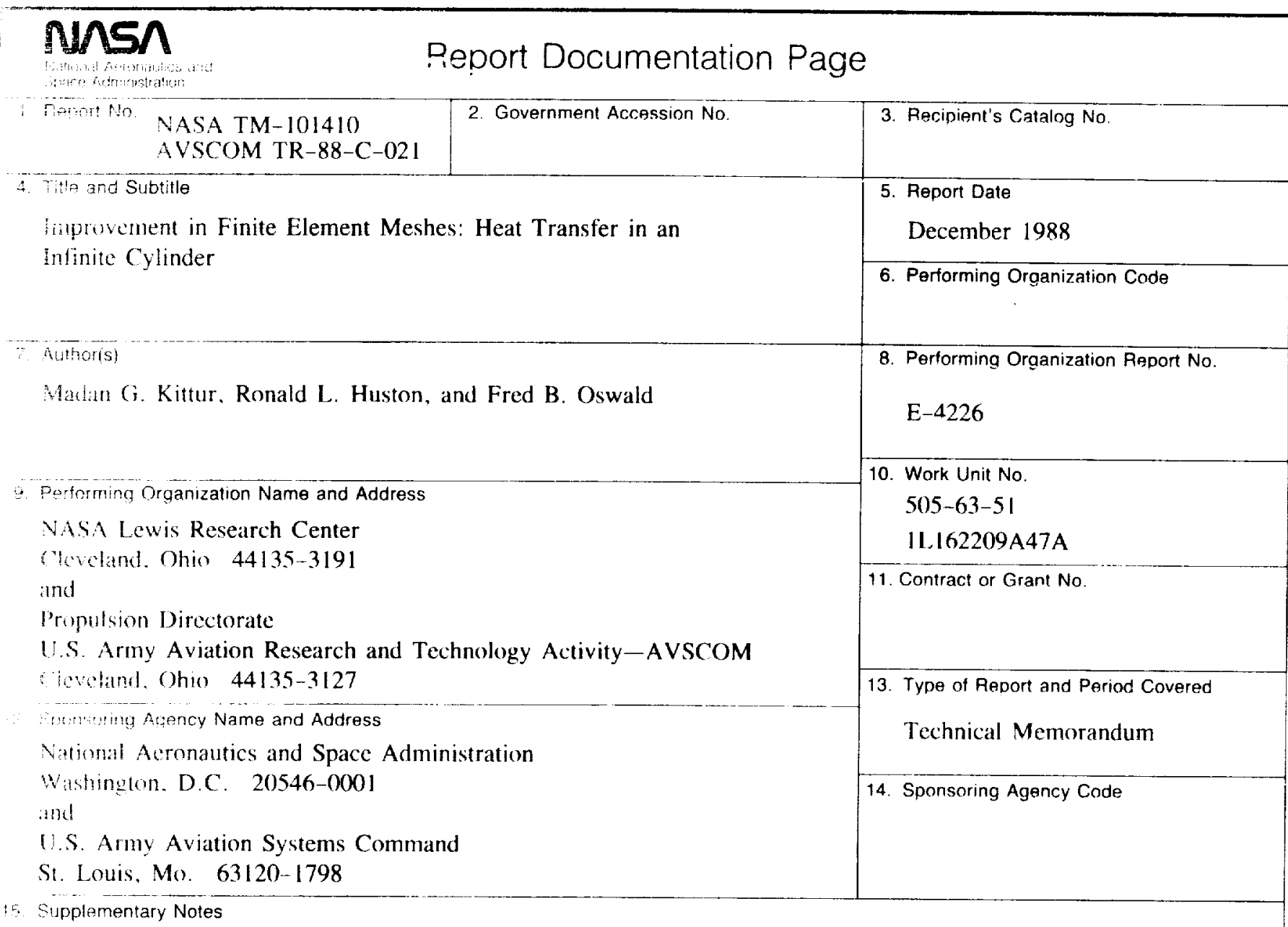

Madan G. Kittur and Ronald L. Huston, University of Cincinnati, Department of Mechanical and Industrial Engineering. Cincinnati, Ohio 45221-0072 (work funded under NASA Grant NSG-3188); Fred B. Oswald, VASA Lewis Research Center.

16. Abstract

This paper presents an extension of a structural finite element mesh improvement techniuue to heat conctuction amalysis. The mesh improvement concept was originally presented by Prager in studying tapered, axially loaded hars. It was further developed by Kittur. et al., who showed that an improved mesh can be obtained by ninimizing the trace of the stiffness matrix. In this paper these procedures are extended and applied to the analysis of heat conduction in an infinitely long hollow circular cylinder.

17. Key Words (Suggested by Author(s))

Finits element

Mesh

Grid optimization

Mesh refinement
8. Distribution Statement

Unclassified-Unlimited

Subject Catcgory 37 


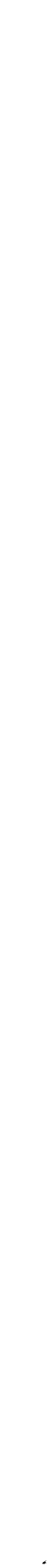
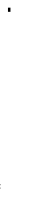
National Aeronautics and Space Administration

Lewis Research Center

Cleveland. Ohio 44135

\section{Oncid Bustness}

Penaly for Pitvato Uso \$\$00
SECONO CLASS MAIL

ADDRESS CORRECTION REQUESTED
||||| National Aeronautics and

Space Administration NASA-451 